\section{DE MINIMIS NON CURAT LEX}

\section{The Natural History of Viruses}

By C. H. Andrewes. (The World Naturalist.) Pp. viii + $237+41$ plates. (London: Weidenfeld and Nicolson, 1967.) 55s. net.

More than a hundred years has gone by since the first publication of the Origin of Species, a work whose contents have been so frequently quoted as an excuse for man's inhumanity to man that it has become one of the seminal books of world literature. But during that same century it has also been shown many times that even the unremitting pressures of natural selection sometimes help the meek to survive. Nature is not always red in tooth and claw, and parasites, in particular, exemplify the principle. A parasite which is successful from the point of view of the survival and dissemination of its own species can be one that does little harm to its host. The dividing line between successful parasitism and commensalism-the concept of the tolerated guest-is as arbitrary as the iron curtain.

In this book Sir Christopher Andrewes calls on a lifetime of experience of the devious ways of viruses to sustain the contention that even they are subject to the inexorable Darwinian law: that they, just like other organisms, have their natural history; hence the title of this book, written with wit and a clarity of style that should be a model to those that follow him. Although writing primarily for laymen, he never compromises on fact, or takes refuge in obscurity, so that his main thesis is wholly acceptable, even to professional colleagues. A wealth of data is assembled to show that viruses have to struggle for existence like any other organism. 'They use all sorts of dodges to obtain access to new hosts and to survive hard times. But viruses differ from all other parasites in that they do not replicate by themselves. They are copied by the living cells they inhabit. Moreover, it is a cliché of pathology that virus lesions do not appear until virus replication is already over. So the primary target of natural selection must be the multicellular organism of which the infected cell forms a part. Selection will only affect the virus within it if the host succumbs before sufficient virus can be made and disseminated, and the successful virus will be one that can persuade its host to produce and excrete a vast quantity of virus particles. Whether the host survives or not is irrelevant in this context; if enough rats succeed in leaving the ship, who cares if it sinks or not? Host mortality will only affect the evolutionary fate of a virus if its onslaught on the host species is so fierce that later virus populations die out through lack of new victims to sustain them. It can be argued that a virus which is less totally destructive, but which still kills a large proportion of its hosts, may even have an evolutionary advantage. First, it will avoid a too rapid spread of immunity through the host species; and second, the more virus there is, the greater will be the chance that new mutants may arise, capable perhaps of attacking new species, or of surviving until new susceptible individuals of the original host species become available.

But when I had finished his book I began to wonder whether in fact this was the only way to assess the importance, in nature, of this fascinating collection of infectious agents. Do viruses obey evolutionary laws because they are organisms? Or is it that such laws describe the behaviour of all things that have reached a certain level of complexity? In this sense, evolution is as inevitable a description of the behaviour of organized matter as Newton's laws of motion. The mere presence, within the primeval prebiotic soup, of a minor constituent with a thermodynamic advantage will ensure its eventual dominance. No one would suggest that such compounds are organisms, or indeed living in any sense, and it is perhaps more appropriate to describe their behaviour in physico-chemical terms.
All this would be mere quibbling were it not that one of the dangers of the "organismal" approach to viruses is that it can blind one to their unique character. Their special position was recognized many years ago by S. E. Luria when he referred to the life of viruses as "parasitism at the genetic level", and it is this aspect of their behaviour that has fascinated virologists over the past ten years. Sir Christopher Andrewes, however, rightly reminds us that there is much more to virology than gift-wrapped packages of rogue nucleic acids. The law of evolution may not care for such littlo things, but we must never abandon his way of looking at them.

\section{F. K. SANDERS}

\section{NMR, NQR AND EPR}

\section{Magnetic Resonance Spectroscopy}

By Harry G. Hecht. (Wiley Series in Pure and Applied Spectroscopy.) Pp. viii +163 . New York and London: John Wiley and Sons, 1967.) $45 s$.

VIRTUALLY the whole of NMR, NQR and EPR spectroscopy is covered in 160 pages, and thirty of these summarize a considerable amount of quantum mechanies. The book is the latest of a series on pure and applied spectroscopy and deals with a larger area than any of its predecessors in less than half the space of the shortest of them! Here is the book's weakness-too much in too little space. Topies mentioned include solid state NMR, pulsed radiofrequency fields, electron-nucleus double resonance, electron and nuclear relaxation, as well as the commonly used concepts such as chemical shift, spin coupling, $g$ tensor and so on.

The book is aimed at the undergraduate-graduate overlap region as a "survey of the field of magnetic resonance spectroscopy as a whole that is geared to the interests of a chemist ..." and to such students who "find it necessary to rely on magnetic resonance data. ..." There is no doubt that a general discussion of the relevance to chemistry of this form of spectroseopy should be part of a chemist's education, but the considerab'e amount of mathematical derivation limits its value here. Only forty reforences (mainly to books) are given, but these simply follow chapters without specific connexion to the text, so the reader will find original papers only with diffieulty.

The author has briefly discussed most of the areas of the subject ehemists are likely to meet, so the book will serve quickly to widen the perspective of mathematically inclined students with a limited acquaintance of magnetic resonance.

R. Bramley

\section{STUDENT'S INTERFEROMETRY}

\section{Interferometry}

By W. H. Steel. (Cambridge Monographs on Physies.) Pp. ix + 271. (London: Cambridge University Press, 1967.) 60s. net; $\$ 11.50$.

THIs well written book attempts to cover quite a formidable subject in eleven chapters and succeeds reasonably well in doing so. The whole approach diffors somewhat from that of older long accepted texts of interferometry. It is certainly well up to dato. The second, third and fourth chapters are mathematical, dealing essentially with Fourier transforms (so popular today), diffraction and coherence. This then is an introductory theoretical basis of wave theory leading on to what is more usually meant by interferometry. This kind of approach is a growing practice now in optics. Whether it helps to clarify the situation for a student is another matter. I am not sure that it does. This introductory theoretical section is well written and compact but will certainly not be easy for the beginnor. 